\title{
Validation of Simultaneous Quantitative Method of HIV Protease Inhibitors Atazanavir, Darunavir and Ritonavir in Human Plasma by UPLC-MS/MS
}

\author{
Tulsidas Mishra ${ }^{1}$ and Pranav S. Shrivastav ${ }^{2}$ \\ ${ }^{1}$ Chemistry Department, Kadi Sarva Vishwavidyalaya, Gandhinagar 382015, India \\ ${ }^{2}$ Department of Chemistry, School of Sciences, Gujarat University, Ahmedabad 380009, India
}

Correspondence should be addressed to Pranav S. Shrivastav; pranav_shrivastav@yahoo.com

Received 31 August 2013; Accepted 24 October 2013; Published 23 January 2014

Academic Editors: T. Kaneta, S. Lee, and Y. Lu

Copyright (C) 2014 T. Mishra and P. S. Shrivastav. This is an open access article distributed under the Creative Commons Attribution License, which permits unrestricted use, distribution, and reproduction in any medium, provided the original work is properly cited.

\begin{abstract}
Objectives. HIV protease inhibitors are used in the treatment of patients suffering from AIDS and they act at the final stage of viral replication by interfering with the HIV protease enzyme. The paper describes a selective, sensitive, and robust method for simultaneous determination of three protease inhibitors atazanavir, darunavir and ritonavir in human plasma by ultra performance liquid chromatography-tandem mass spectrometry. Materials and Methods. The sample pretreatment consisted of solid phase extraction of analytes and their deuterated analogs as internal standards from $50 \mu \mathrm{L}$ human plasma. Chromatographic separation of analytes was performed on Waters Acquity UPLC C18 $(50 \times 2.1 \mathrm{~mm}, 1.7 \mu \mathrm{m})$ column under gradient conditions using $10 \mathrm{mM}$ ammonium formate, $\mathrm{pH} 4.0$, and acetonitrile as the mobile phase. Results. The method was established over a concentration range of $5.0-6000 \mathrm{ng} / \mathrm{mL}$ for atazanavir, $5.0-5000 \mathrm{ng} / \mathrm{mL}$ for darunavir and $1.0-500 \mathrm{ng} / \mathrm{mL}$ for ritonavir. Accuracy, precision, matrix effect, recovery, and stability of the analytes were evaluated as per US FDA guidelines. Conclusions. The efficiency of sample preparation, short analysis time, and high selectivity permit simultaneous estimation of these inhibitors. The validated method can be useful in determining plasma concentration of these protease inhibitors for therapeutic drug monitoring and in high throughput clinical studies.
\end{abstract}

\section{Introduction}

Ever since the introduction of protease inhibitors (PIs) in 1995 for the treatment of human immunodeficiency virus (HIV) and their subsequent relevance in highly active antiretroviral therapy (HAART), there is an increase in the life expectancy of HIV infected patients and thus reduction in mortality of infected patients [1]. The HAART therapy relies on combination of several drugs in a daily regimen which includes one or more nucleoside reverse transcriptase inhibitors (NRTIs), together with one or two PIs and one NNRTI. This combination helps in minimizing occurrence of viral resistance and in preventing adverse events [2]. Standard guidelines recommend that initial treatment of patients with HIV-1 infection under HAART therapy should have a ritonavir- (RTV-) boosted protease inhibitor, usually darunavir (DRV) or atazanavir (ATV) together with other antiretrovirals (ARVs) [3]. Due to rapid emergence of resistance for NNRTIs, the use of PIs has increased for the treatment of HIV infection. PIs mainly affect the aspartic protease enzyme of human immunodeficiency virus (HIV $\mathrm{PR}$ ) which is responsible for the cleavage of the viral Gag and Gag-Pol polyprotein precursors into mature, functional viral enzymes, and structural proteins [4].

RTV, a first-generation highly potent PI was designed by Abbot Laboratories and was approved by US FDA in 1996. It is active against HIV-1 as well as HIV-2 proteases and is currently used as a booster to optimize pharmacokinetics of other PIs and to prolong their therapeutic effects. It is sold under the brand name Norvir [5]. The second-generation PIs like ATV and DRV are used to inhibit those protease species which are resistant to the inhibitors of the first generation. Further, both the drugs are well tolerated with minimum side effects. ATV, an azapeptide, was developed 
originally by Ciba-Geigy and sold under the trade name Reyataz by Bristol-Myers Squibb. It was approved in 2003, and it shows a unique HIV resistance profile and favourable pharmacokinetics which allows once-daily dosing [6]. DRV is a nonpeptidic HIV PI, developed by Tibotec BVBA and approved by US FDA in 2006, and is commercially available as Prezista [7]. It has broad specificity against mutated and highly resistant protease species mainly due to its ability to fit to the proposed "substrate envelope" within the active site [1]. DRV is 100 times more effective for wild-type HIV-1 protease compared to several other PIs [8].

Accurate determination of PIs plasma concentration is vital for pharmacokinetic measurements, optimization of dosages, and drug-drug interaction studies. In spite of several clinical advantages of these PIs, they have a very narrow therapeutic index and hence the need for therapeutic drug monitoring is essential [9]. The literature presents several methods to determine ATV [10-13], DRV [14-17] and RTV $[18,19]$ as a single analyte using ELISA, HPLC-UV, LCMS/MS, and UPLC-MS/MS techniques. Checa et al. [2] have reviewed methods for determination of antiretroviral drugs with special emphasis on the principal analytical strategies for dealing with clinical samples up to 2008. Since then there are numerous other methods which describe simultaneous determination of these drugs together with other PIs and antiretroviral drugs [20-31] in diverse matrices like human plasma [20-26], human whole blood and dried blood spots [27, 28], peripheral blood mononuclear cells $[29,30]$, and mouse serum and tissues [31]. Recently, an excellent review article has also been reported on bioanalytical methods developed for ARVs in tissues and different body fluids like amniotic fluid, cervicovaginal fluid, cerebrospinal fluid, extracellular cerebral fluid, saliva, and male seminal plasma/serum [32]. The bulk of these methods have employed LC-MS/MS [20, 22-25, 27-30] technique for the simultaneous analysis of ARVs, while the use of UPLC-MS/MS methodology for analysis has been a subject of very few reports [21, 26, 31]. Yadav et al. [21] analyzed lopinavir (LPV) and RTV in human plasma by UPLC-ESI-MS/MS and studied its application for a bioequivalence study in healthy subjects. In another report, three protease inhibitors indinavir (IDV), LPV, and RTV were determined simultaneously by UPLC-MS/MS [26]. Huang et al. [31] quantified nanoformulated RTV, IDV, ATV, and efavirenz in mouse serum and tissues by UPLC-MS/MS. However, there is no UPLC-MS/MS method for simultaneous determination of ATV, DRV and RTV in human plasma.

Ultra performance liquid chromatography (UPLC) has given a different dimension to separation science by building on the established principles of liquid chromatography. It functions on the use of sub, $2 \mu$ particle size to provide increased resolution, sensitivity, and throughput. UPLC can reduce the analysis time and improve chromatographic performance compared to HPLC by controlling system volumes and peak dispersion. Additionally, solvent consumption can also be minimized compared to conventional $4.6 \mathrm{~mm}$ id columns [33]. Thus, in the present work, a robust, selective, and rapid UPLC-MS/MS method has been developed and fully validated for reliable measurement of ATV, DRV, and RTV in human plasma. The method employs only $50 \mu \mathrm{L}$ plasma volume for sample preparation and demonstrates excellent chromatographic efficiency $(2.0 \mathrm{~min})$. It can be readily applied in a high throughput clinical setting and also for therapeutic drug monitoring.

\section{Materials and Methods}

2.1. Chemicals. Reference standards of atazanavir (99.6\%), darunavir (99.2\%), and ritonavir (99.3\%) and their deuterated internal standards (ISs) atazanavir-d6 (99.1\%), darunavird9 (99.5\%) and ritonavir-d6 (99.0\%) were procured from Clearsynth Labs Pvt. Ltd. (Mumbai, India). HPLC grade methanol and acetonitrile were obtained from Mallinckrodt Baker, S.A.de C.V. (Estado de Mexico, Mexico). Bioultragrade ammonium formate and LC-MS grade formic acid were purchased from Sigma-Aldrich (St. Louis, MO, USA). Oasis HLB ( $1 \mathrm{cc}, 30 \mathrm{mg}$ ) extraction cartridges were from Waters Corporation (Milford, MA, USA). Water used in the study was prepared from Milli-Q water purification system from Millipore (Bangalore, India). Blank human plasma in $\mathrm{K}_{3}$ EDTA was obtained from Supratech Micropath (Ahmedabad, India) and was stored at $-20^{\circ} \mathrm{C}$ until use.

2.2. Liquid Chromatography and Mass Spectrometric Conditions. The chromatographic analysis of ATV, DRV, and RTV was carried out on Waters Acquity UPLC system (MA, USA) employing BEH C18 $(50 \times 2.1 \mathrm{~mm}, 1.7 \mu \mathrm{m})$ analytical column, maintained at $35^{\circ} \mathrm{C}$. Separation was achieved under a gradient program using a mobile phase consisting of (A) $10 \mathrm{mM}$ ammonium formate, $\mathrm{pH} 4.0$, adjusted with formic acid in water, and (B) acetonitrile at a flow rate of $0.300 \mathrm{~mL} / \mathrm{min}$ with $50 \%$ flow splitting. Initially, for up to $0.8 \mathrm{~min}$, the ratio of A and B was kept at 50:50 $(v / v)$ and from $0.8 \mathrm{~min}$ to $1.2 \mathrm{~min}$ the ratio was changed to $30: 70(v / v)$. The system was then equilibrated to the initial conditions up to $2.0 \mathrm{~min}$. The sample manager temperature was maintained at $5^{\circ} \mathrm{C}$ with an alarm band of $\pm 3^{\circ} \mathrm{C}$ and the average pressure of the system was 6000 psi.

Detection and quantitation of analytes and ISs were carried out using multiple reaction monitoring (MRM) for protonated precursor $\rightarrow$ product ion transitions on Quattro Premier XE mass spectrometer from Waters-Micro Mass Technologies (MA, USA) in the positive electrospray ionization mode. Source dependent and compound dependent mass parameters optimized and MRM transitions for analytes and ISs are summarized in Table 1. MassLynx software version 4.1 was used to control all parameters of UPLC and MS.

2.3. Standard Stock, Calibration Standards, and Quality Control Sample Preparation. The standard stock solutions of ATV, DRV, and RTV $(1.0 \mathrm{mg} / \mathrm{mL}$ each) were prepared by dissolving requisite amounts in methanol. Their intermediate stock solutions and working solutions were made by appropriate dilution of their stock solutions with methanol: water $(50: 50, v / v)$. Calibration standards (CSs) and quality control (QC) samples were made by spiking blank plasma with appropriate volumes of working solutions. The concentration 
TABLE 1: Optimized mass spectrometer parameters, MRM transitions, and chromatographic performance.

\begin{tabular}{|c|c|c|c|c|c|c|}
\hline Parameters & ATV & ATV-d6 & DRV & DRV-d9 & RTV & RTV-d6 \\
\hline \multicolumn{7}{|c|}{ Mass spectrometry parameters } \\
\hline \multicolumn{7}{|c|}{ Source dependent } \\
\hline Capillary voltage (kV) & \multicolumn{6}{|c|}{4.0} \\
\hline Extractor voltage (V) & \multicolumn{6}{|c|}{3.0} \\
\hline RF lens $(V)$ & \multicolumn{6}{|c|}{0.0} \\
\hline Source temperature $\left({ }^{\circ} \mathrm{C}\right)$ & \multicolumn{6}{|c|}{110} \\
\hline Desolvation temperature $\left({ }^{\circ} \mathrm{C}\right)$ & \multicolumn{6}{|c|}{400} \\
\hline Desolvation gas flow $(\mathrm{L} / \mathrm{h})$ & \multicolumn{6}{|c|}{$900 \pm 10$} \\
\hline Cone gas flow $(\mathrm{L} / \mathrm{h})$ & \multicolumn{6}{|c|}{$100 \pm 10$} \\
\hline \multicolumn{7}{|l|}{ Analyzer parameters } \\
\hline LM 1/HM 1 resolution & \multicolumn{6}{|c|}{$15.0 / 15.0$} \\
\hline Ion energy 1 /ion energy 2 & \multicolumn{6}{|c|}{$0.2 / 1.0$} \\
\hline Entrance/exit & \multicolumn{6}{|c|}{$-1.0 / 0.1$} \\
\hline LM 2/HM 2 resolution & \multicolumn{6}{|c|}{$14.0 / 14.0$} \\
\hline \multicolumn{7}{|c|}{ Compound dependent } \\
\hline Cone voltage $(\mathrm{V})$ & 30 & 29 & 25 & 27 & 30 & 26 \\
\hline Collision energy $(\mathrm{eV})$ & 44 & 42 & 17 & 17 & 20 & 21 \\
\hline Dwell time (ms) & 200 & 200 & 200 & 200 & 200 & 200 \\
\hline MRM transition $(m / z)$ & $705.3 / 167.9$ & $711.2 / 168.0$ & $548.1 / 392.0$ & $557.1 / 401.0$ & $721.3 / 296.3$ & $727.4 / 302.3$ \\
\hline \multicolumn{7}{|c|}{ Chromatography characteristics } \\
\hline Retention time (min) & 0.69 & 0.69 & 1.02 & 1.01 & 1.54 & 1.54 \\
\hline Capacity factors & 1.15 & 1.16 & 2.18 & 2.15 & 3.81 & 3.82 \\
\hline Theoretical plates & 396 & 398 & 851 & 836 & 1683 & 1682 \\
\hline
\end{tabular}

ATV: atazanavir; ATV-d6: atazanavir-d6; DRV: darunavir; DRV-d9: darunavir-d9; RTV: ritonavir; RTV-d6: ritonavir-d6.

RF: radio frequency; LM: low mass; HM: high mass.

of CSs was 5.0, 10, 50, 100, 200,400, 750, 1500, 3000, and $6000 \mathrm{ng} / \mathrm{mL}$ for ATV, 5.0, 10, 50, 100, 200, 400, 800, 1200, 2500 , and $5000 \mathrm{ng} / \mathrm{mL}$ for DRV, and 1.0, 2.0, 5.0, 10, 20, 40, 80, 125, 250 and $500 \mathrm{ng} / \mathrm{mL}$ for RTV. The QC samples were prepared at five concentration levels as follows: HQC, high quality control: ATV (4800 ng/mL), DRV (4000 ng/mL), and RTV (400 ng/mL); MQC-1, medium quality control-1: ATV (2400 ng/mL), DRV (2000 ng/mL), and RTV (200 ng/mL); MQC-2, medium quality control-2: ATV (150 ng/mL), DRV (150 ng/mL), and RTV (30 ng/mL); LQC, low quality control: $\operatorname{ATV}(15 \mathrm{ng} / \mathrm{mL}), \operatorname{DRV}(15 \mathrm{ng} / \mathrm{mL})$ and RTV $(3.0 \mathrm{ng} / \mathrm{mL})$; and LLOQ QC, lower limit of quantification quality control: $\operatorname{ATV}(5.0 \mathrm{ng} / \mathrm{mL}), \operatorname{DRV}(5.0 \mathrm{ng} / \mathrm{mL})$ and RTV $(1.0 \mathrm{ng} / \mathrm{mL})$. The stock solutions of ISs $(1.0 \mathrm{mg} / \mathrm{mL})$ were prepared by dissolving $10.0 \mathrm{mg}$ of ISs in $10.0 \mathrm{~mL}$ of methanol. Their working solution $(500 \mathrm{ng} / \mathrm{mL}$ for ATV and DRV; $50 \mathrm{ng} / \mathrm{mL}$ for RTV) was prepared by appropriate dilution of the stock solution in methanol: water $(50: 50 \mathrm{v} / \mathrm{v})$. The stock solutions were stored at $5^{\circ} \mathrm{C}$, while calibration standards and quality control samples were stored at $-70^{\circ} \mathrm{C}$ until use.

2.4. Sample Extraction Protocols. Prior to analysis, all calibration and quality control samples were thawed and allowed to equilibrate at room temperature. To an aliquot of $50 \mu \mathrm{L}$ of spiked plasma sample, $50 \mu \mathrm{L}$ internal standard was added and vortexed for approximately $10 \mathrm{~s}$. Further, $100 \mu \mathrm{L}$ of $0.1 \%$ formic acid was added and vortexd for another $10 \mathrm{~s}$. The samples were then loaded on Oasis HLB extraction cartridges which were preconditioned with $1 \mathrm{~mL}$ methanol followed by $1 \mathrm{~mL}$ of water. Thereafter the cartridges were washed with $1 \mathrm{~mL}, 5 \%$ methanol in water, and then dried for $2 \mathrm{~min}$ by applying nitrogen $\left(1.72 \times 10^{5} \mathrm{~Pa}\right)$ at $2.4 \mathrm{~L} / \mathrm{min}$ flow rate. Elution of analytes and ISs from the cartridges was carried out with $500 \mu \mathrm{L}$ of $0.2 \%$ formic acid in methanol into prelabeled tubes. The eluate was evaporated to dryness in a thermostatically controlled water-bath maintained at $40^{\circ} \mathrm{C}$ under a gentle stream of nitrogen for $5 \mathrm{~min}$. After drying, the residue was reconstituted in $200 \mu \mathrm{L}$ of reconstitution solution (10 mM ammonium formate: acetonitrile $(20: 80, v / v))$ and $5 \mu \mathrm{L}$ was used for injection in the chromatographic system.

2.5. Procedures for Method Validation. Validation was performed following US FDA guidelines [34]. System suitability was tested by injecting six consecutive injections using aqueous standard mixture of analytes and ISs at the start of each batch during method validation. The precision (\% CV) of system suitability test was found in the range of 0.13 to $0.24 \%$ for the retention time and 0.85 to $2.96 \%$ for the area response for all the analytes and ISs. System performance was studied by injecting one extracted blank (without analytes and ISs) and one extracted LLOQ sample with ISs at the beginning of each analytical batch. The signal-to-noise ratio for system performance was $\geq 22$ for all the three analytes. Autosampler carryover was evaluated by sequentially injecting extracted 
blank plasma $\rightarrow$ upper limit of quantitation (ULOQ) sample $\rightarrow$ two extracted blank plasma sample $\rightarrow$ LLOQ sample $\rightarrow$ extracted blank plasma at the start and end of each batch. Selectivity of the method was assessed for potential matrix interferences in ten batches ( 6 normal lots of $\mathrm{K}_{3}$ EDTA, 2 haemolysed, and 2 lipemic) of blank human plasma by extraction and inspection of the resulting chromatograms for interfering peaks.

Linearity of the method was assessed from five, ten-point calibration lines. A quadratic, $1 / x^{2}$, least-squares regression algorithm was tested to plot the peak area ratio (analyte/IS) from multiple reaction monitoring versus concentration. The linear equations were then used to calculate the predicted concentrations in all samples within the analytical runs. The correlation coefficient for each calibration curve must be $\geq 0.99$ for all the analytes. The lowest standard on the calibration line was accepted as the LLOQ, if the analyte response was at least ten times more than that of extracted blank plasma. Reinjection reproducibility for extracted samples was also checked by reinjection of an entire analytical run after storage at $5^{\circ} \mathrm{C}$.

Intraday accuracy and precision were evaluated by replicate analysis of plasma samples on the same day. The analytical run consisted of a calibration curve and six replicates of HQC, MQC-1/2, LOQ, and LLOQ samples. The interday accuracy and precision were assessed by analysis of five precision and accuracy batches on three consecutive validation days. The precision (\% CV) at each concentration level from the nominal concentration should not be greater than $15 \%$. Similarly, the mean accuracy should be within $85-$ $115 \%$, except for the LLOQ, where it can be within $80-120 \%$ of the nominal concentration.

Ion suppression/enhancement effects on the MRM LCMS/MS sensitivity were evaluated by postcolumn analyte infusion experiment. Briefly, a standard solution containing a mixture of ATV, DRV, and RTV (at MQC-1 level) was infused after column into the mobile phase at $10 \mu \mathrm{L} / \mathrm{min}$ employing infusion pump. Aliquots of $5 \mu \mathrm{L}$ of extracted control blank plasma sample were then injected into the column and chromatograms were acquired for the analytes.

Extraction recovery of the analytes and ISs from human plasma was evaluated in six replicates by comparing the mean peak area responses of preextraction fortified samples to those of postextraction fortified samples representing 100\% recovery. Matrix effect, expressed as matrix factors (MFs), was assessed by comparing the mean area response of postextraction fortified samples with mean area of solutions prepared in mobile phase solutions (neat standards). ISnormalized MFs (analyte/IS) were calculated to access the variability of the assay due to matrix effects. To evaluate the relative matrix effect in different plasma lots, postextraction fortified samples were prepared in triplicate at LLOQ concentration and assessed for accuracy (\%) and precision (\% CV). In order to meet acceptance criteria, the $\%$ CV must be $\leq 15 \%$ for the analytes.

Stock solutions of analytes and ISs were checked for short-term stability at room temperature and long-term stability at $5^{\circ} \mathrm{C}$. Stability results in plasma were evaluated by measuring the area ratio response (analyte/IS) of stability samples against freshly prepared comparison standards with identical concentration. The solutions were considered stable if the deviation from nominal value was within $\pm 10.0 \%$. Autosampler (wet extract), bench top (at room temperature), and freeze-thaw (at $-20^{\circ} \mathrm{C}$ and $-70^{\circ} \mathrm{C}$ ) and long-term stability (at $-20^{\circ} \mathrm{C}$ and $-70^{\circ} \mathrm{C}$ ) were performed at LQC and HQC level using six replicates. The stability samples were quantified against freshly prepared quality control samples. Stability data were acceptable if the $\% \mathrm{CV}$ of the replicate determinations did not exceed $15.0 \%$ and the mean accuracy value was within $\pm 15.0 \%$ of the nominal value.

Method ruggedness was verified with two batches; the first batch was analyzed on two columns with different batch numbers, while the second batch was analyzed by different analysts who were not part of method validation. The ability to dilute samples which could be above the upper limit of the calibration range was validated by analyzing six replicates samples containing 20000/20000/1000 ng/mL of ATV/DRV/RTV after five-/tenfold dilution, respectively. The precision and accuracy for dilution reliability was determined by comparing the samples against freshly prepared calibration curve standards.

\section{Results}

3.1. Autosampler Carryover, Linearity, Accuracy and Precision, Limit of Detection, and Limit of Quantitation. The autosampler carryover results showed minimal carryover of analyte, $\leq 0.12 \%$ of LLOQ area in the extracted blank sample after injection of ULOQ sample for the analytes. The calibration curves were linear over the concentration range of 5.0-6000 ng/mL for ATV, 5.0-5000 ng/mL for DRV, and $1.0-500 \mathrm{ng} / \mathrm{mL}$ for RTV with a correlation coefficient $\left(r^{2}\right) \geq 0.9995$ for all the analytes (Figure 1). The mean linear equations obtained were as follows: ATV: $y=(0.0018 \pm$ $0.0002) x+(0.0007 \pm 0.0003), \mathrm{DRV}: y=(0.0025 \pm 0.0003) x+$ $(0.0002 \pm 0.0001)$, and RTV: $y=(0.0211 \pm 0.0020) x+$ $(0.0021 \pm 0.0002)$. The accuracy and precision (\% CV) for the calibration curve standards ranged from 95.67 to $105.33 \%$ and from 2.19 to 6.34 for ATV, from 93.70 to $103.00 \%$ and from 1.68 to 5.66 for DRV and from 98.28 to $103.33 \%$ and from 0.61 to 5.92 for RTV. The limit of detection (LOD) and lower limit of quantitation (LLOQ) were 1.5 and $5.0 \mathrm{ng} / \mathrm{mL}$ for ATV and DRV and 0.35 and $1.0 \mathrm{ng} / \mathrm{mL}$ for RTV respectively. The signalto-noise ratio for ATV, DRV and RTV was $22: 1$ at LLOQ and $10: 1$ at LOD respectively.

\subsection{Intra- and Interbatch Accuracy and Precision, Extraction} Recovery and Matrix Effect. The intrabatch and interbatch precision (\% CV) across five quality control samples ranged from 0.8 to 7.3 over the analytical range and the accuracy was from 91.3 to $104.4 \%$ for all the analytes (Table 2). The extraction recovery and matrix factors for the analytes are presented in Tables 3 and 4, respectively. The mean extraction recovery ranged from 97.35 to 101.06 for ATV, from 97.73 to $102.30 \%$ for DRV, and from 98.37 to $102.12 \%$ for RTV across QC levels. The presence of unmonitored and 


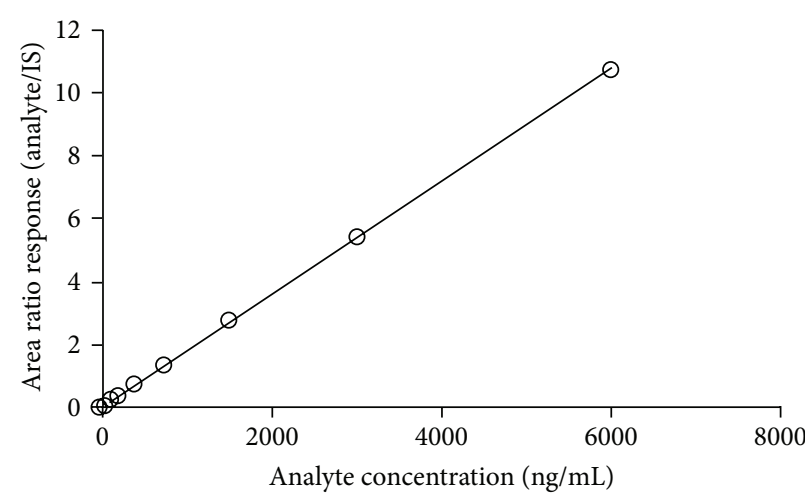

(a)

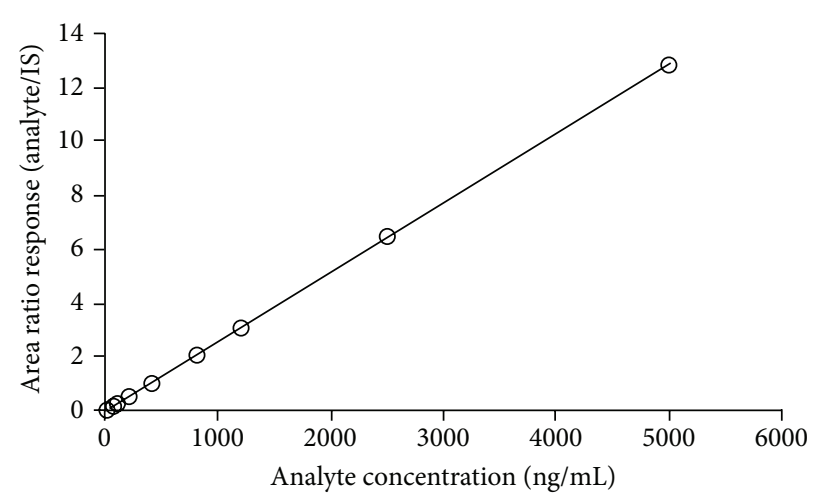

(b)

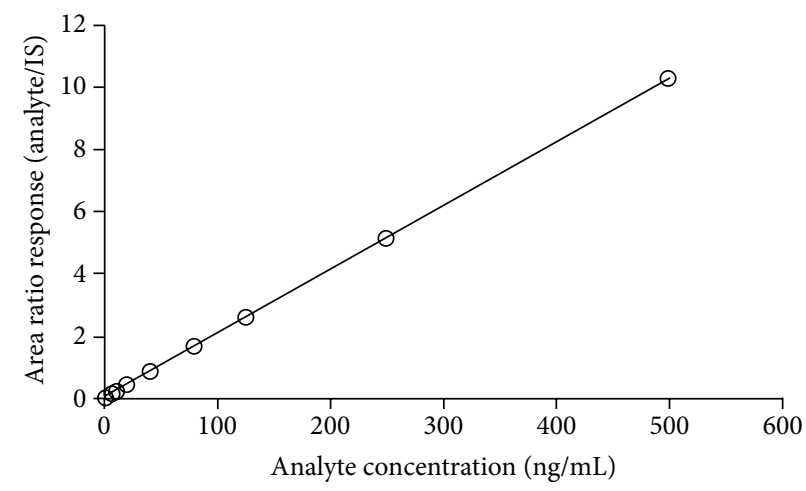

(c)

FIGURE 1: Calibration curves for (a) atazanavir, (b) darunavir, and (c) ritonavir.

TABLE 2: Intrabatch and interbatch precision and accuracy for atazanavir, darunavir, and ritonavir.

\begin{tabular}{|c|c|c|c|c|c|c|}
\hline \multirow[b]{2}{*}{$\begin{array}{l}\text { QC level (nominal } \\
\text { concentration) }\end{array}$} & \multicolumn{3}{|c|}{ Intrabatch $(n=6 ;$ single batch $)$} & \multicolumn{3}{|c|}{ Interbatch $(n=30 ; 6$ from each batch $)$} \\
\hline & $\begin{array}{c}\text { Mean } \\
\text { concentration } \\
\text { observed }(\mathrm{ng} / \mathrm{mL})\end{array}$ & $\% \mathrm{CV}$ & $\%$ Accuracy & $\begin{array}{c}\text { Mean } \\
\text { concentration } \\
\text { found for } 5 \\
\text { batches }(\mathrm{ng} / \mathrm{mL})\end{array}$ & $\% \mathrm{CV}$ & $\%$ Accuracy \\
\hline \multicolumn{7}{|c|}{ Atazanavir } \\
\hline LLOQ QC $(5.0 \mathrm{ng} / \mathrm{mL})$ & 5.21 & 6.3 & 104.1 & 5.05 & 5.1 & 101.0 \\
\hline LQC $(15 \mathrm{ng} / \mathrm{mL})$ & 14.5 & 4.5 & 96.8 & 14.9 & 1.5 & 99.4 \\
\hline MQC-2 (150 ng/mL) & 142.8 & 2.8 & 95.2 & 153.9 & 4.3 & 102.6 \\
\hline MQC-1 (2400 ng/mL) & 2362 & 3.4 & 98.4 & 2482 & 0.8 & 103.4 \\
\hline HQC (4800 ng/mL) & 4886 & 3.3 & 101.8 & 4814 & 3.2 & 100.3 \\
\hline \multicolumn{7}{|c|}{ Darunavir } \\
\hline LLOQ QC $(5.0 \mathrm{ng} / \mathrm{mL})$ & 4.89 & 6.9 & 97.8 & 4.97 & 7.3 & 99.5 \\
\hline LQC $(15 \mathrm{ng} / \mathrm{mL})$ & 14.3 & 4.1 & 95.3 & 14.7 & 3.2 & 98.1 \\
\hline MQC-2 (150 ng/mL) & 149.5 & 1.9 & 99.7 & 153.0 & 1.4 & 102.0 \\
\hline MQC-1 $(2000 \mathrm{ng} / \mathrm{mL})$ & 2088 & 3.0 & 104.4 & 1936 & 3.5 & 96.8 \\
\hline HQC (4000 ng/mL) & 3832 & 2.3 & 95.8 & 3808 & 1.4 & 95.2 \\
\hline \multicolumn{7}{|c|}{ Ritonavir } \\
\hline LLOQ QC (1.0 ng/mL) & 0.95 & 5.8 & 95.0 & 0.93 & 5.8 & 92.7 \\
\hline LQC $(3.0 \mathrm{ng} / \mathrm{mL})$ & 2.78 & 4.9 & 92.7 & 2.86 & 1.3 & 95.2 \\
\hline MQC-2 (30 ng/mL) & 30.7 & 1.9 & 102.2 & 30.9 & 2.9 & 103.2 \\
\hline MQC-1 (200 ng/mL) & 182.6 & 3.8 & 91.3 & 189.2 & 4.4 & 94.6 \\
\hline HQC (400 ng/mL) & 385.6 & 4.9 & 96.4 & 404.4 & 1.9 & 101.1 \\
\hline
\end{tabular}

CV: coefficient of variation; LLOQ: lower limit of quantitation; LQC: low quality control; MQC: medium quality control; HQC: high quality control. 
TABLE 3: Extraction recovery of atazanavir, darunavir, and ritonavir from human plasma.

\begin{tabular}{|c|c|c|c|c|c|c|c|c|c|}
\hline \multirow{3}{*}{ QC level } & \multicolumn{3}{|c|}{ Atazanavir } & \multicolumn{3}{|c|}{ Darunavir } & \multicolumn{3}{|c|}{ Ritonavir } \\
\hline & \multicolumn{2}{|c|}{ Area response } & \multirow{2}{*}{$\begin{array}{l}\text { Extraction } \\
\text { recovery, \% }(B / A)\end{array}$} & \multicolumn{2}{|c|}{ Area response } & \multirow{2}{*}{$\begin{array}{l}\text { Extraction } \\
\text { recovery, \% }(B / A)\end{array}$} & \multicolumn{2}{|c|}{ Area response } & \multirow{2}{*}{$\begin{array}{l}\text { Extraction } \\
\text { recovery, \% }(B / A)\end{array}$} \\
\hline & $A$ & $B$ & & $A$ & $B$ & & $A$ & $B$ & \\
\hline LQC & 9773 & 9514 & 97.35 & 20074 & 19861 & 98.94 & 6074 & 6118 & 100.72 \\
\hline MQC-2 & 104201 & 102458 & 98.33 & 183148 & 187367 & 102.30 & 64148 & 63283 & 98.65 \\
\hline MQC-1 & 1654728 & 1694608 & 101.06 & 2491752 & 2435246 & 97.73 & 390617 & 384267 & 98.37 \\
\hline \multirow[t]{2}{*}{ HQC } & 3382518 & 3408890 & 100.16 & 4922563 & 4847816 & 98.48 & 821547 & 838931 & 102.12 \\
\hline & \multicolumn{3}{|c|}{ Atazanavir-d6 } & \multicolumn{3}{|c|}{ Darunavir-d9 } & \multicolumn{3}{|c|}{ Ritonavir-d6 } \\
\hline \multirow[t]{2}{*}{ QC level } & \multicolumn{2}{|c|}{ Area response } & \multirow{2}{*}{$\begin{array}{l}\text { Extraction } \\
\text { recovery, \% }(B / A)\end{array}$} & \multicolumn{2}{|c|}{ Area response } & \multirow{2}{*}{$\begin{array}{l}\text { Extraction } \\
\text { recovery, \% }(B / A)\end{array}$} & \multicolumn{2}{|c|}{ Area response } & \multirow{2}{*}{$\begin{array}{l}\text { Extraction } \\
\text { recovery, \% }(B / A)\end{array}$} \\
\hline & A & $B$ & & A & $B$ & & A & B & \\
\hline LQC & 338514 & 335727 & 99.18 & 530681 & 531079 & 100.07 & 105065 & 103329 & 98.35 \\
\hline MQC-2 & 348240 & 339419 & 97.47 & 510151 & 525715 & 103.05 & 102738 & 102443 & 99.71 \\
\hline MQC-1 & 341729 & 346341 & 101.35 & 541747 & 535298 & 98.81 & 98827 & 96357 & 97.50 \\
\hline HQC & 331508 & 337897 & 101.93 & 520571 & 517827 & 99.47 & 97538 & 99945 & 102.47 \\
\hline
\end{tabular}

LQC: low quality control; MQC: medium quality control; HQC: high quality control.

$A$ : mean area response of six replicate samples prepared by spiking in extracted blank plasma.

$B$ : mean area response of six replicate samples prepared by extracting spiked blank plasma.

TABLE 4: Matrix factor for atazanavir, darunavir, and ritonavir.

\begin{tabular}{|c|c|c|c|c|c|c|c|c|c|}
\hline \multirow{3}{*}{ QC level } & \multicolumn{3}{|c|}{ Atazanavir } & \multicolumn{3}{|c|}{ Darunavir } & \multicolumn{3}{|c|}{ Ritonavir } \\
\hline & \multicolumn{2}{|c|}{ Area response } & \multirow{2}{*}{ Matrix factor $(B / A)$} & \multicolumn{2}{|c|}{ Area response } & \multirow{2}{*}{ Matrix factor $(B / A)$} & \multicolumn{2}{|c|}{ Area response } & \multirow{2}{*}{ Matrix factor $(B / A)$} \\
\hline & $A$ & $B$ & & $A$ & $B$ & & $A$ & $B$ & \\
\hline LQC & 10061 & 9773 & 0.97 & 19583 & 20074 & 1.03 & 6137 & 6074 & 0.99 \\
\hline MQC-2 & 103108 & 104201 & 1.01 & 189378 & 183148 & 0.97 & 63019 & 64148 & 1.02 \\
\hline MQC-1 & 1694608 & 1654728 & 0.98 & 2487277 & 2491752 & 1.00 & 404237 & 390617 & 0.97 \\
\hline HQC & 3408890 & 3382518 & 0.99 & 5047023 & 4922563 & 0.98 & 846102 & 821547 & 0.97 \\
\hline \multirow{3}{*}{ QC level } & \multicolumn{3}{|c|}{ Atazanavir-d6 } & \multicolumn{3}{|c|}{ Darunavir-d9 } & \multicolumn{3}{|c|}{ Ritonavir-d6 } \\
\hline & \multicolumn{2}{|c|}{ Area response } & \multirow{2}{*}{ Matrix factor $(B / A)$} & \multicolumn{2}{|c|}{ Area response } & \multirow{2}{*}{ Matrix factor $(B / A)$} & \multicolumn{2}{|c|}{ Area response } & \multirow{2}{*}{ Matrix factor $(B / A)$} \\
\hline & A & $B$ & & A & $B$ & & A & $B$ & \\
\hline LQC & 347253 & 338514 & 0.97 & 531482 & 530681 & 1.00 & 103941 & 105065 & 1.01 \\
\hline MQC-2 & 344253 & 348240 & 1.01 & 523378 & 510151 & 0.97 & 104106 & 102738 & 0.99 \\
\hline MQC-1 & 346748 & 341729 & 0.99 & 534156 & 541747 & 1.01 & 100574 & 98827 & 0.98 \\
\hline HQC & 340675 & 331508 & 0.97 & 532074 & 520571 & 0.98 & 100078 & 97538 & 0.97 \\
\hline
\end{tabular}

LQC: low quality control; MQC: medium quality control; HQC: high quality control.

$A$ : mean area response of six replicate samples prepared in mobile phase (neat samples).

$B$ : mean area response of six replicate samples prepared by spiking in extracted blank plasma.

coeluting compounds from the matrix can affect the accuracy, precision, and overall reliability of a validated method. It is recommended that evaluation of matrix factor (MF) can help to assess the matrix effect. Further, matrix effect needs to be checked in lipemic and haemolysed plasma samples in addition to normal $\mathrm{K}_{3}$ EDTA plasma. The IS-normalized MFs using stable-isotope labelled IS should be close to unity because of the similarities in the chemical properties and elution times for the analytes and ISs. The IS-normalized MFs ranged from 0.99 to1.03 for all the analytes.

The relative matrix effect was also evaluated in six independent plasma lots which consisted of four normal $\mathrm{K}_{3}$ EDTA, one haemolysed and one lipemic plasma at LLOQ level. The accuracy and precision values for all the analytes varied from 98.82 to $100.86 \%$ and from 1.76 to $3.82 \%$, respectively (Table 5).

3.3. Analyte Stability, Method Ruggedness, and Dilution Reliability. The short-term and long-term stability of stock solutions of analytes and ISs were stable at room temperature for up to $7 \mathrm{~h}$ and for a minimum period of 7 days, respectively. The stability of all the analytes in plasma was established at appropriate temperatures and storage periods required for clinical analysis. The detailed results for bench top, wet extract, and freeze-thaw and long-term stability of the analytes are summarized in Table 6 . The precision and accuracy values observed for method ruggedness (for different columns and analysts) were between 3.5 and 7.6\% 
TABLE 5: Relative matrix effect in different lots of human plasma at LLOQ level.

\begin{tabular}{|c|c|c|c|c|c|c|c|c|}
\hline $\begin{array}{l}\text { Analyte } \\
\text { (nominal concentration) }\end{array}$ & $\begin{array}{r}\mathrm{M} \epsilon \\
\text { 1) } \mathrm{K}_{3} \mathrm{EDTA}\end{array}$ & \multicolumn{4}{|c|}{ Mean area response in six plasma lots (mean of three replicates) } & s) & $\begin{array}{l}\text { Coefficient of } \\
\text { variation }(\%)\end{array}$ & Accuracy (\%) \\
\hline Atazanavir $(5.0 \mathrm{ng} / \mathrm{mL})$ & 3415 & 3368 & 3418 & 3497 & 3625 & 3707 & 3.82 & 100.86 \\
\hline Darunavir $(5.0 \mathrm{ng} / \mathrm{mL})$ & 6245 & 6351 & 6471 & 6152 & 6283 & 6373 & 1.76 & 98.82 \\
\hline Ritonavir $(1.0 \mathrm{ng} / \mathrm{mL})$ & 2004 & 2048 & 2105 & 2067 & 2117 & 2037 & 2.06 & 99.23 \\
\hline
\end{tabular}

LLOQ: lower limit of quantitation.

TABLE 6: Stability of atazanavir, darunavir, and ritonavir in human plasma under different conditions.

\begin{tabular}{|c|c|c|c|c|c|c|}
\hline \multirow[b]{2}{*}{ Storage conditions } & \multicolumn{2}{|c|}{ Atazanavir } & \multicolumn{2}{|c|}{ Darunavir } & \multicolumn{2}{|c|}{ Ritonavir } \\
\hline & $\begin{array}{c}\text { Mean of six } \\
\text { stability samples } \\
(\mathrm{ng} / \mathrm{mL}) \pm \mathrm{SD}\end{array}$ & $\%$ change & $\begin{array}{c}\text { Mean of six } \\
\text { stability samples } \\
(\mathrm{ng} / \mathrm{mL}) \pm \mathrm{SD}\end{array}$ & $\%$ change & $\begin{array}{c}\text { Mean of six } \\
\text { stability samples } \\
(\mathrm{ng} / \mathrm{mL}) \pm \mathrm{SD}\end{array}$ & $\%$ change \\
\hline \multicolumn{7}{|c|}{ Bench top stability at ambient temperature; $14 \mathrm{~h}$} \\
\hline LQC & $15.23 \pm 0.20$ & 1.33 & $15.41 \pm 0.44$ & 2.73 & $2.954 \pm 0.189$ & -1.53 \\
\hline HQC & $4885 \pm 155$ & 1.78 & $4215 \pm 215$ & 5.38 & $417.1 \pm 24.65$ & 4.28 \\
\hline \multicolumn{7}{|c|}{ Wet extract stability; $24 \mathrm{~h}, 5^{\circ} \mathrm{C}$} \\
\hline LQC & $15.42 \pm 0.32$ & 2.67 & $15.24 \pm 0.94$ & 1.60 & $3.068 \pm 0.135$ & 2.27 \\
\hline HQC & $4893 \pm 267$ & 1.94 & $3975 \pm 176$ & -0.63 & $418.2 \pm 16.75$ & 4.55 \\
\hline \multicolumn{7}{|c|}{ Freeze and thaw stability in plasma; 6 cycles, $-20^{\circ} \mathrm{C}$} \\
\hline LQC & $14.74 \pm 0.28$ & -2.11 & $15.71 \pm 0.76$ & 4.73 & $2.865 \pm 0.143$ & -4.50 \\
\hline HQC & $4717 \pm 149$ & -1.73 & $4058 \pm 138$ & 1.45 & $415.6 \pm 21.67$ & -3.65 \\
\hline \multicolumn{7}{|c|}{ Freeze and thaw stability in plasma; 6 cycles, $-70^{\circ} \mathrm{C}$} \\
\hline LQC & $14.96 \pm 0.51$ & -0.67 & $14.85 \pm 0.82$ & -1.00 & $2.981 \pm 0.176$ & -0.63 \\
\hline HQC & $4687 \pm 178$ & -2.35 & $4156 \pm 202$ & 3.90 & $378.6 \pm 14.39$ & 3.90 \\
\hline \multicolumn{7}{|c|}{ Long-term stability in plasma; 60 days, $-20^{\circ} \mathrm{C}$} \\
\hline LQC & $15.31 \pm 0.43$ & 2.02 & $15.28 \pm 0.79$ & 1.87 & $3.073 \pm 0.159$ & 2.43 \\
\hline HQC & $4924 \pm 231$ & 2.58 & $4187 \pm 237$ & 4.68 & $378.6 \pm 17.83$ & -5.35 \\
\hline \multicolumn{7}{|c|}{ Long-term stability in plasma; 60 days, $-70^{\circ} \mathrm{C}$} \\
\hline LQC & $15.53 \pm 0.27$ & 3.34 & $14.98 \pm 0.56$ & -0.13 & $3.043 \pm 0.213$ & 1.43 \\
\hline HQC & $5032 \pm 97$ & 4.83 & $3947 \pm 191$ & -1.33 & $374.9 \pm 13.74$ & -6.28 \\
\hline
\end{tabular}

LQC: low quality control; HQC: high quality control.

SD: standard deviation; $n$ : number of replicates at each level.

$\%$ change $=(($ mean stability samples - mean comparison samples $) /$ mean comparison samples $) \times 100$.

and between 92.7 and $105.9 \%$ for ATV, between 2.5 and $8.6 \%$ and between 97.7 and 102.9\% for DRV and between 2.6 and 7.9\% and between 99.1 and $104.4 \%$ for RTV respectively. The dilution integrity experiment was performed with an aim of validating the dilution test to be carried out on higher analyte concentration above ULOQ, which could be found in clinical samples. The precision and accuracy values for $1 / 5$ th and $1 / 10$ th dilution ranged from 5.0 to $5.6 \%$ and from 102.1 to $105.1 \%$ for all the analytes.

\section{Discussion}

Method Development. The present work was executed using electrospray ionization (ESI) in the positive ionization mode as ATV, DRV, and RTV have several secondary amino groups which can be readily protonated. Q1 mass spectra of
ATV, DRV, RTV, ATV-d6, DRV-d9, and RTV-d6 contained protonated precursor $[\mathrm{M}+\mathrm{H}]^{+}$ions at $m / z$ 705.2, 548.1, 721.3, $711.2,557.1$ and 727.4 respectively as reported in our previous work $[13,17,21]$. The most abundant and consistent product ions in Q3 mass spectra for ATV, DRV and RTV were observed at $m / z 167.9,392.0$ and 296.3 by applying collision energy of 44, 17 and $20 \mathrm{eV}$ respectively. These product ion fragments can be attributed to the substructure 4-(pyridin2-yl)phenyl methyl group in ATV (Figure 2(a)), elimination of $p$-aminophenyl sulfonyl group from the precursor ion of DRV (Figure 2(b)), and breaking of amide linkage in RTV (Figure 2(c)) respectively. All mass parameters were suitably optimized to obtain a stable and adequate response for the analytes. A dwell time of $200 \mathrm{~ms}$ was sufficient and no interference was observed between the MRMs of the analytes and their deuterated ISs. 


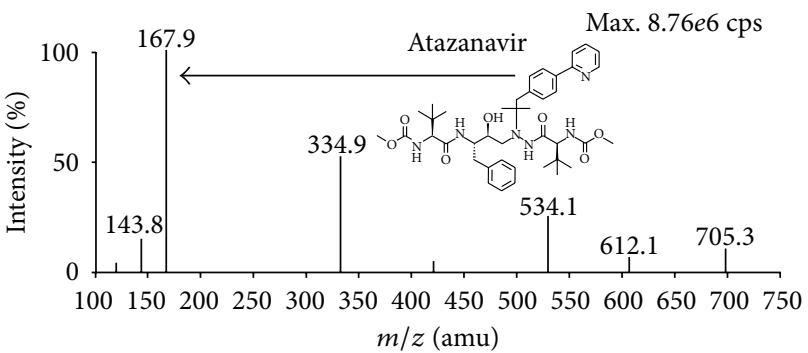

(a)

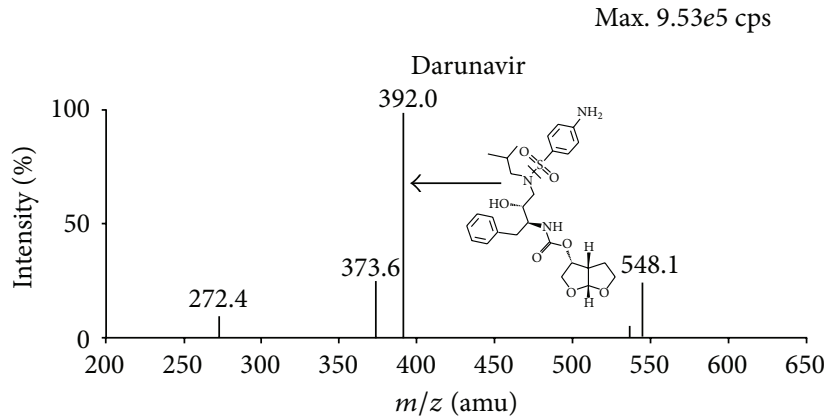

(b)

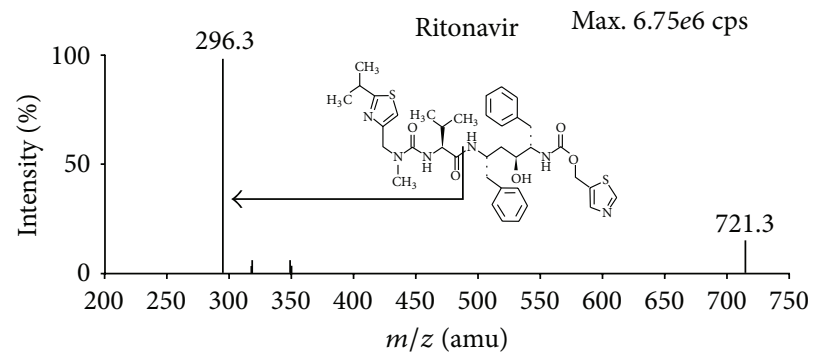

(c)

Figure 2: Product ion mass spectra of (a) atazanavir $(m / z 705.3 \rightarrow 167.9$, scan range 100-750 amu) (b) darunavir $(m / z 548.1 \rightarrow 392.0$, scan range 200-650 amu), and (c) ritonavir $(\mathrm{m} / z 721.3 \rightarrow 296.3$, scan range 200-750 amu) in the positive ionization mode.
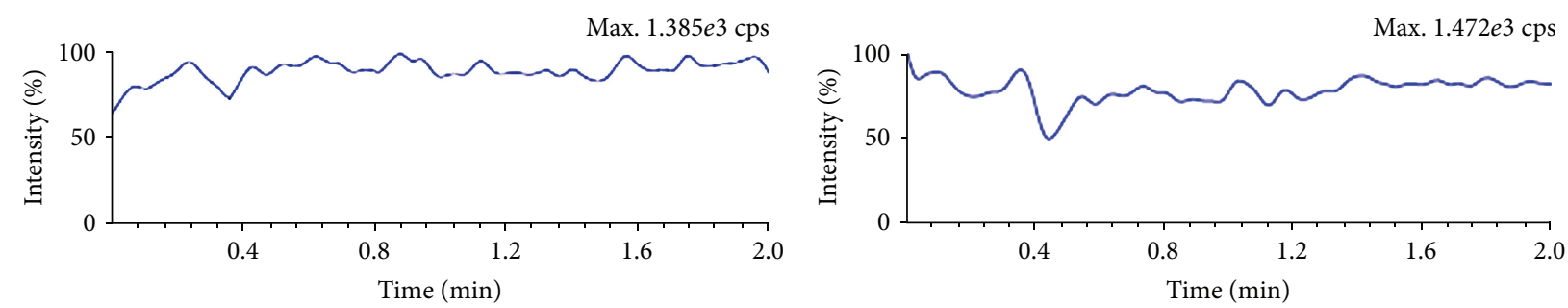

(a)
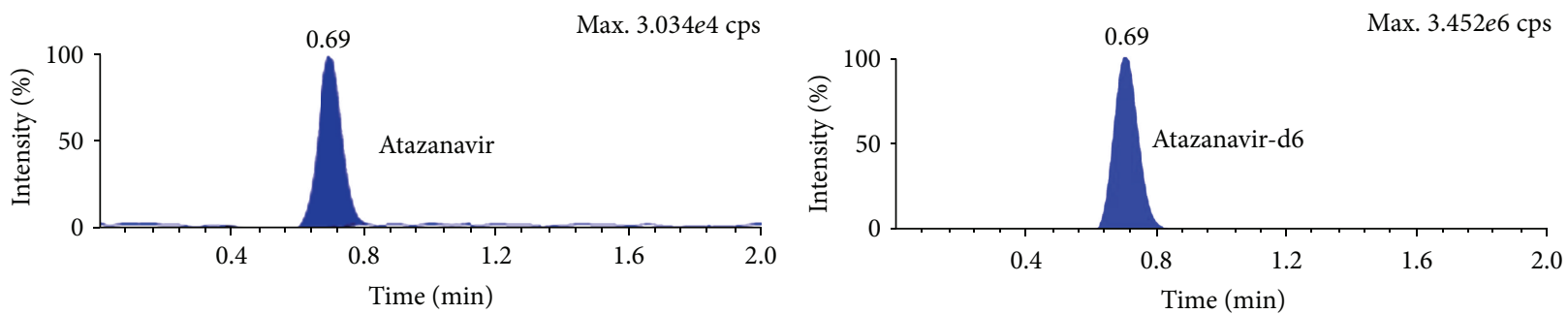

(b)
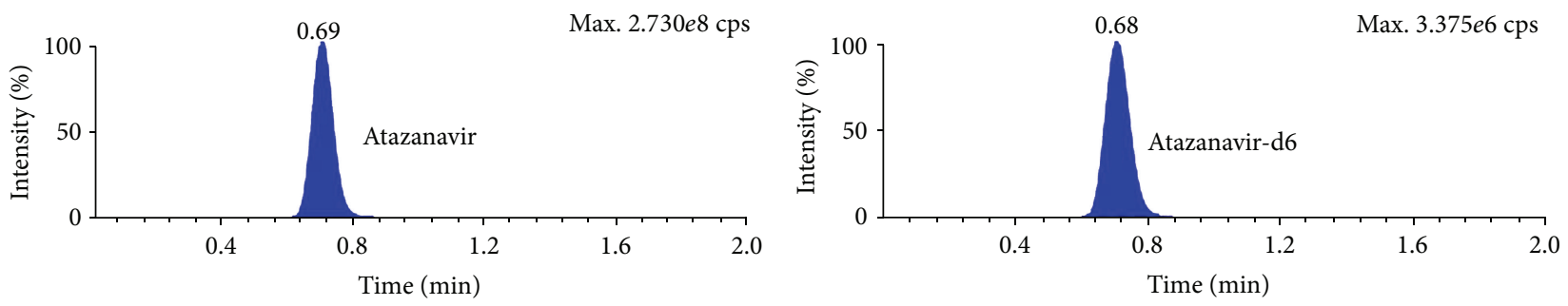

(c)

FIGURE 3: MRM ion chromatograms of atazanavir in (a) double blank plasma (without analyte and IS), (b) at LLOQ and atazanavir-d6, and (c) in real subject sample. 

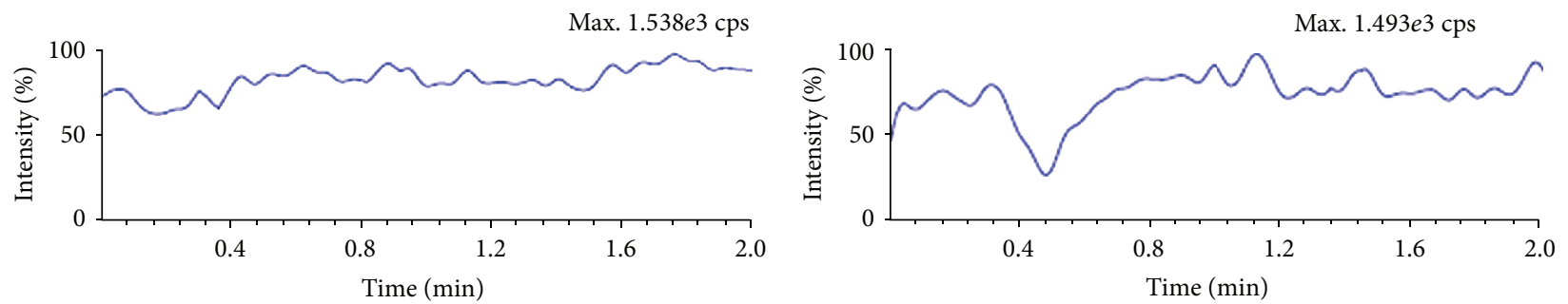

(a)
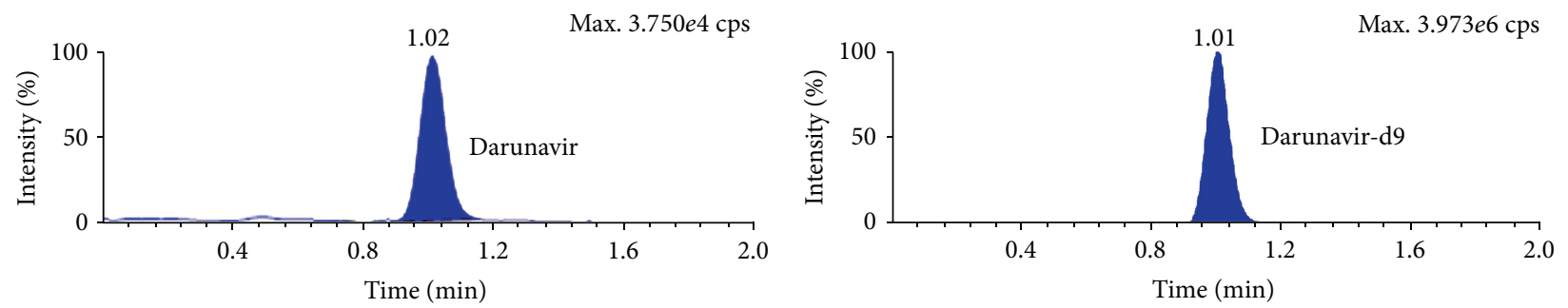

(b)
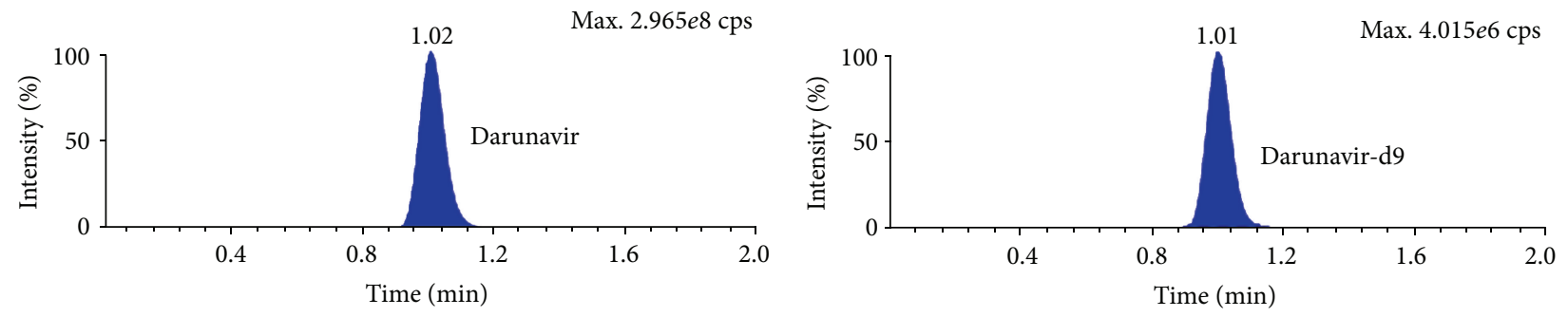

(c)

FIGURE 4: MRM ion chromatograms of darunavir in (a) double blank plasma (without analyte and IS), (b) at LLOQ and darunavir-d9, and (c) in real subject sample.

Methods which deal with the simultaneous determination of these three PIs in human plasma have used protein precipitation (PP) as the extraction technique $[22,25$, 35]. Others which deal with simultaneous determination of plasma ATV and RTV [36-39] or DRV and RTV [27] together with other ARVs have employed either PP or liquidliquid extraction (LLE). Notari et al. [40] determined 16 anti-HIV drugs in human plasma by HPLC using solid-phase extraction (SPE). In our earlier work with ATV [13] and RTV [21], SPE was carried out for their separate determination, while LLE with methyl tert-butyl ether was used for DRV [17]. Furthermore, an extensive study was carried to optimize the extraction procedure due to matrix interference during PP and LLE for selective determination of ATV from human plasma [13]. In the present work, SPE was tested on Oasis HLB cartridge for their simultaneous determination in human plasma. Addition of $0.1 \%$ formic acid helped in breaking drug-protein binding, with quantitative and precise recovery for the analytes at all QC levels from $50 \mu \mathrm{L}$ plasma. The plasma volume used for processing is much less compared to reported procedures for simultaneous determination of PIs [20, 22, 25, 36-40].

The chromatographic conditions were initiated to have short run time, adequate response and good peak shapes under isocratic conditions on Waters Acquity UPLC BEH
$\mathrm{C} 18(50 \times 2.1 \mathrm{~mm}, 1.7 \mu \mathrm{m})$ column . Based on our earlier work for ATV and RTV [13, 21], various combinations of organic solvents (methanol/acetonitrile) together with ammonium formate/formic acid buffer in the $\mathrm{pH}$ range 3.5-5.5 were tried. However, the run time was more than $4.0 \mathrm{~min}$ for baseline resolution of the analytes. Thus, gradient elution was tried using ammonium formate and acetonitrile, and the best mobile phase conditions were obtained using solvent system (A) $10 \mathrm{mM}$ ammonium formate, $\mathrm{pH} 4.0$ adjusted with formic acid and (B) acetonitrile to achieve adequate retention, peak shape, adequate response and complete separation. All the analytes were eluted within $2.0 \mathrm{~min}$ with retention time of $0.69,1.02$ and 1.54 for ATV, DRV and RTV respectively. Further, the reproducibility of retention times for the analytes, expressed as \% CV was $\leq 0.52 \%$ for 100 injections on the same column. The capacity factors and number of theoretical plates which are used to characterize the performance of chromatography are summarized in Table 1 . The resolution factor $\left(R_{s}\right)$ between ATV and DRV and DRV and RTV was 2.06 and 3.25 respectively. Further, use of deuterated internal standards helped to compensate any variability during extraction and UPLC-MS/MS analysis. MRM chromatograms for double blank plasma (without analyte and IS), at LLOQ and a real subject sample in Figures 3, 4 and 5 confirm the selectivity of the method to distinguish and quantify the 

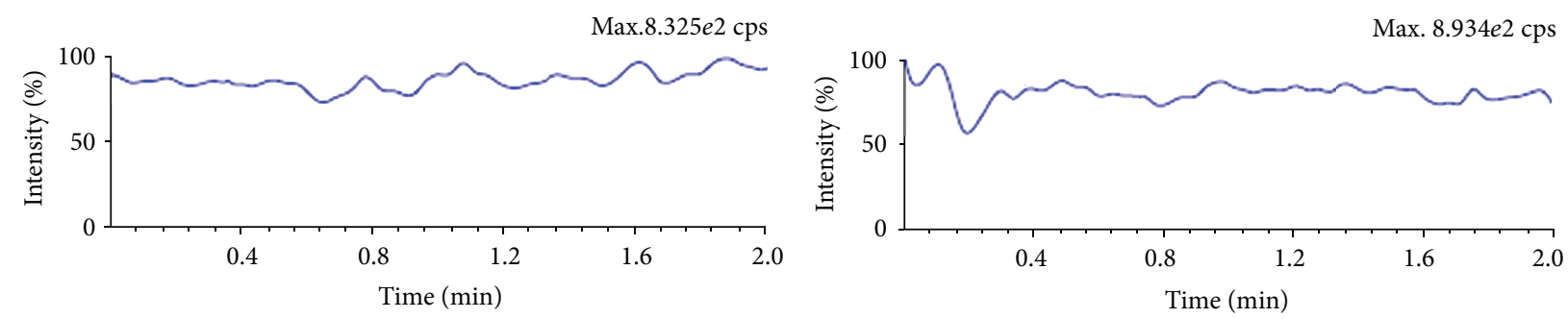

(a)
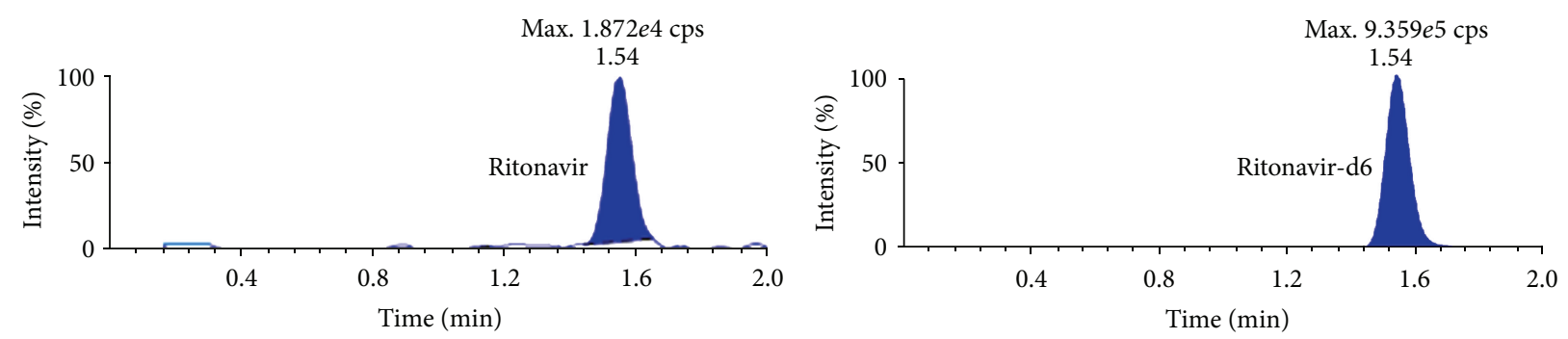

(b)
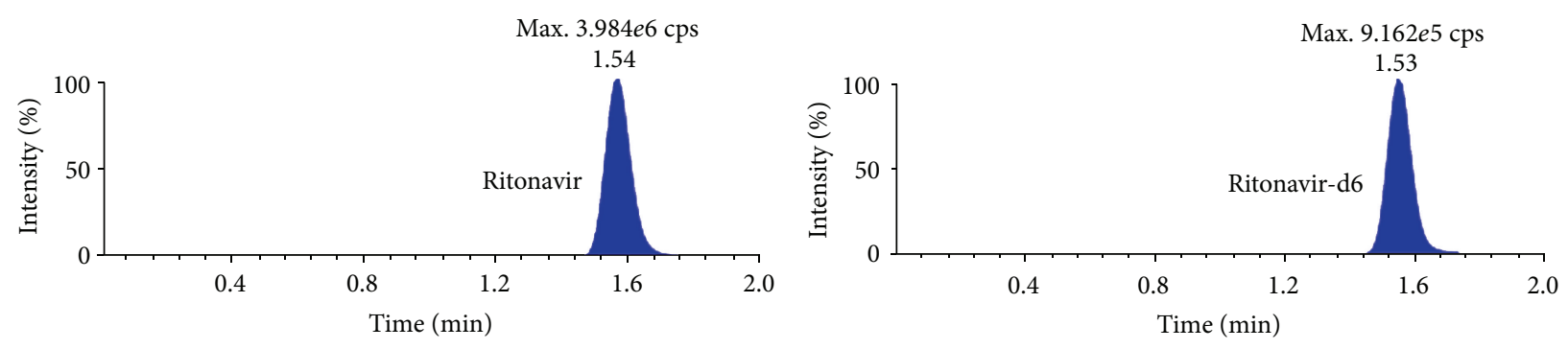

(c)

FIGURE 5: MRM ion chromatograms of ritonavir in (a) double blank plasma (without analyte and IS), (b) at LLOQ and ritonavir-d6, and (c) in real subject sample.

analyte from endogenous components in the plasma matrix. Moreover, there was no interference of matrix at the retention time of analytes or ISs as evident from postcolumn infusion study.

\section{Conclusions}

In spite of several existing assay methods for the simultaneous determination of PIs, very few studies have reported the use of UPLC-MS/MS for therapeutic drug monitoring. In this present work, we have developed and fully validated a reliable, precise and sensitive UPLC-MS/MS method for the simultaneous quantification of atazanavir, darunavir and ritonavir in human plasma. The assay is superior to reported methods with respect to sensitivity, analysis time and matrix effect. The method is rapid and requires small plasma volume for sample processing. Use of deuterated internal standards further reinforces the accuracy and precision of the proposed method and can be suitable for pharmacokinetic/bioequivalence studies.

\section{Conflict of Interests}

The authors declare that there is no conflict of interests regarding the publication of this paper.

\section{Acknowledgment}

The authors are thankful to the management of Veeda Clinical Research Pvt. Ltd. for their support, infrastructure, and quality execution of the work.

\section{References}

[1] J. Pokorná, L. Machala, P. Řezáčová, and Jan Konvalinka, "Current and novel inhibitors of HIV protease," Viruses, vol. 5, no. 3, pp. 1209-1239, 2009.

[2] A. Checa, R. Oliver, S. Hernández-Cassou, and J. Saurina, "Determination of HIV drugs in biological matrices: a review," Analytica Chimica Acta, vol. 647, no. 1, pp. 1-13, 2009.

[3] M. A. Thompson, J. A. Aberg, P. Cahn et al., "Antiretroviral treatment of adult HIV infection: 2010 recommendations of 
the International AIDS Society-USA panel," Journal of the American Medical Association, vol. 304, no. 3, pp. 321-333, 2010.

[4] K. Kitidee, S. Nangola, S. Hadpech, W. Laopajpon, W. Kasinrerk, and C. Tayapiwatana, "A drug discovery platform: a simplified immunoassay for analyzing HIV protease activity," Journal of Virological Methods, vol. 186, no. 1-2, pp. 21-29, 2012.

[5] N. Von Hentig, "Lopinavir/ritonavir: appraisal of its use in HIV therapy," Drugs of Today, vol. 43, no. 4, pp. 221-247, 2007.

[6] C. Le Tiec, A. Barrail, C. Goujard, and A.-M. Taburet, "Clinical pharmacokinetics and summary of efficacy and tolerability of atazanavir," Clinical Pharmacokinetics, vol. 44, no. 10, pp. 10351050, 2005.

[7] E. Lefebvre and C. A. Schiffer, "Resilience to resistance of HIV-1 protease inhibitors: profile of darunavir," AIDS Reviews, vol. 10, no. 3, pp. 131-142, 2008.

[8] N. M. King, M. Prabu-Jeyabalan, E. A. Nalivaika, P. Wigerinck, M.-P. de Béthune, and C. A. Schiffer, "Structural and thermodynamic basis for the binding of TMC114, a next-generation human immunodeficiency virus type 1 protease inhibitor," Journal of Virology, vol. 78, no. 21, pp. 12012-12021, 2004.

[9] R. E. Aarnoutse, J. M. Schapiro, C. A. B. Boucher, Y. A. Hekster, and D. M. Burger, "Therapeutic drug monitoring: an aid to optimising response to antiretroviral drugs?” Drugs, vol. 63, no. 8, pp. 741-753, 2003.

[10] R. W. Sparidans, F. Dost, K. M. L. Crommentuyn, A. D. R. Huitema, J. H. M. Schellens, and J. H. Beijnen, "Liquid chromatographic assay for the protease inhibitor atazanavir in plasma," Biomedical Chromatography, vol. 20, no. 1, pp. 72-76, 2006.

[11] A. Loregian, S. Pagni, E. Ballarin, E. Sinigalia, S. G. Parisi, and G. Palù, "Simple determination of the HIV protease inhibitor atazanavir in human plasma by high-performance liquid chromatography with UV detection," Journal of Pharmaceutical and Biomedical Analysis, vol. 42, no. 4, pp. 500-505, 2006.

[12] A. C. Müller and I. Kanfer, "An efficient HPLC method for the quantitative determination of atazanavir in human plasma suitable for bioequivalence and pharmacokinetic studies in healthy human subjects," Journal of Pharmaceutical and Biomedical Analysis, vol. 53, no. 1, pp. 113-118, 2010.

[13] M. Yadav, V. Trivedi, V. Upadhyay et al., "Comparison of extraction procedures for assessment of matrix effect for selective and reliable determination of atazanavir in human plasma by LCESI-MS/MS," Journal of Chromatography B, vol. 885-886, pp. 138-149, 2012.

[14] A. Yilmaz, A. Izadkhashti, R. W. Price et al., "Darunavir concentrations in cerebrospinal fluid and blood in HIV-1infected individuals," AIDS Research and Human Retroviruses, vol. 25, no. 4, pp. 457-461, 2009.

[15] M. Takahashi, Y. Kudaka, N. Okumura, A. Hirano, K. Banno, and T. Kaneda, "The validation of plasma darunavir concentrations determined by the HPLC method for protease inhibitors," Biological and Pharmaceutical Bulletin, vol. 30, no. 10, pp. 19471949, 2007.

[16] L. Goldwirt, S. Chhun, E. Rey et al., "Quantification of darunavir (TMC114) in human plasma by high-performance liquid chromatography with ultra-violet detection," Journal of Chromatography B, vol. 857, no. 2, pp. 327-331, 2007.

[17] A. Gupta, P. Singhal, P. S. Shrivastav, and M. Sanyal, "Application of a validated ultra performance liquid chromatographytandem mass spectrometry method for the quantification of darunavir in human plasma for a bioequivalence study in Indian subjects," Journal of Chromatography B, vol. 879, no. 24, pp. 2443-2453, 2011.

[18] R. M. W. Hoetelmans, M. van Essenberg, M. Profijt, P. L. Meenhorst, J. W. Mulder, and J. H. Beijnen, "High-performance liquid chromatographic determination of ritonavir in human plasma, cerebrospinal fluid and saliva," Journal of Chromatography B, vol. 705, no. 1, pp. 119-126, 1998.

[19] F. Akeb, B. Ferrua, C. Creminon et al., "Quantification of plasma and intracellular levels of the HIV protease inhibitor ritonavir by competitive ELISA," Journal of Immunological Methods, vol. 263, no. 1-2, pp. 1-9, 2002.

[20] A. Fayet, A. Béguin, B. Zanolari et al., "A LC-tandem MS assay for the simultaneous measurement of new antiretroviral agents: raltegravir, maraviroc, darunavir, and etravirine," Journal of Chromatography B, vol. 877, no. 11-12, pp. 1057-1069, 2009.

[21] M. Yadav, R. Rao, H. Kurani, P. Singhal, S. Goswami, and P. S. Shrivastav, "Application of a rapid and selective method for the simultaneous determination of protease inhibitors, lopinavir and ritonavir in human plasma by UPLC-ESI-MS/MS for bioequivalence study in Indian subjects," Journal of Pharmaceutical and Biomedical Analysis, vol. 49, no. 4, pp. 1115-1122, 2009.

[22] J. Martin, G. Deslandes, E. Dailly et al., "A liquid chromatography-tandem mass spectrometry assay for quantification of nevirapine, indinavir, atazanavir, amprenavir, saquinavir, ritonavir, lopinavir, efavirenz, tipranavir, darunavir and maraviroc in the plasma of patients infected with HIV," Journal of Chromatography B, vol. 877, no. 27, pp. 3072-3082, 2009.

[23] F. Myasein, E. Kim, J. Zhang, H. Wu, and T. A. El-Shourbagy, "Rapid, simultaneous determination of lopinavir and ritonavir in human plasma by stacking protein precipitations and saltingout assisted liquid/liquid extraction, and ultrafast LC-MS/MS," Analytica Chimica Acta, vol. 651, no. 1, pp. 112-116, 2009.

[24] A. D’Avolio, M. Simiele, M. Siccardi et al., "HPLC-MS method for the quantification of nine anti-HIV drugs from dry plasma spot on glass filter and their long term stability in different conditions," Journal of Pharmaceutical and Biomedical Analysis, vol. 52, no. 5, pp. 774-780, 2010.

[25] L. Else, V. Watson, J. Tjia et al., "Validation of a rapid and sensitive high-performance liquid chromatography-tandem mass spectrometry (HPLC-MS/MS) assay for the simultaneous determination of existing and new antiretroviral compounds," Journal of Chromatography B, vol. 878, no. 19, pp. 1455-1465, 2010.

[26] T. D. Mishra, H. Kurani, P. Singhal, and P. S. Shrivastav, "Simultaneous quantitation of HIV-protease inhibitors ritonavir, lopinavir and indinavir in human plasma by UPLC-ESIMS-MS," Journal of Chromatographic Science, vol. 50, no. 10, pp. 625-635, 2012.

[27] N. L. Rezk, N. R. White, S. H. Jennings, and A. D. M. Kashuba, "A novel LC-ESI-MS method for the simultaneous determination of etravirine, darunavir and ritonavir in human blood plasma," Talanta, vol. 79, no. 5, pp. 1372-1378, 2009.

[28] R. ter Heine, J. W. Mulder, E. C. M. van Gorp, J. F. P. Wagenaar, J. H. Beijnen, and A. D. R. Huitema, "Clinical evaluation of the determination of plasma concentrations of darunavir, etravirine, raltegravir and ritonavir in dried blood spot samples," Bioanalysis, vol. 3, no. 10, pp. 1093-1097, 2011.

[29] R. ter Heine, M. Davids, H. Rosing et al., "Quantification of HIV protease inhibitors and non-nucleoside reverse transcriptase inhibitors in peripheral blood mononuclear cell lysate using liquid chromatography coupled with tandem mass spectrometry," 
Journal of Chromatography B, vol. 877, no. 5-6, pp. 575-580, 2009.

[30] A. D’Avolio, M. Simiele, M. Siccardi et al., "A HPLC-MS method for the simultaneous quantification of fourteen antiretroviral agents in peripheral blood mononuclear cell of HIV infected patients optimized using medium corpuscular volume evaluation," Journal of Pharmaceutical and Biomedical Analysis, vol. 54, no. 4, pp. 779-788, 2011.

[31] J. Huang, N. Gautam, S. P. R. Bathena et al., "UPLCMS/MS quantification of nanoformulated ritonavir, indinavir, atazanavir, and efavirenz in mouse serum and tissues," Journal of Chromatography B, vol. 879, no. 23, pp. 2332-2338, 2011.

[32] R. di Francesco, G. Maduke, R. Patel, C. R. Taylor, and G. D. Morse, "Antiretroviral bioanalysis methods of tissues and body biofluids," Bioanalysis, vol. 5, no. 3, pp. 351-368, 2013.

[33] S. A. C. Wren and P. Tchelitcheff, "Use of ultra-performance liquid chromatography in pharmaceutical development," Journal of Chromatography A, vol. 1119, no. 1-2, pp. 140-146, 2006.

[34] Guidance for Industry, "Bionanlytical Method Validation," US Department of Health and Human Services, Food and Drug Administration Centre for Drug Evaluation and Research (CDER), Centre for Veterinary Medicine (CVM), 2001.

[35] A. D’Avolio, M. Siccardi, M. Sciandra et al., "HPLC-MS method for the simultaneous quantification of the new HIV protease inhibitor darunavir, and 11 other antiretroviral agents in plasma of HIV-infected patients," Journal of Chromatography B, vol. 859, no. 2, pp. 234-240, 2007.

[36] E. Dailly, F. Raffi, and P. Jolliet, "Determination of atazanavir and other antiretroviral drugs (indinavir, amprenavir, nelfinavir and its active metabolite M8, saquinavir, ritonavir, lopinavir, nevirapine and efavirenz) plasma levels by high performance liquid chromatography with UV detection," Journal of Chromatography B, vol. 813, no. 1-2, pp. 353-358, 2004.

[37] L. Dickinson, L. Robinson, J. Tjia, S. Khoo, and D. Back, "Simultaneous determination of HIV protease inhibitors amprenavir, atazanavir, indinavir, lopinavir, nelfinavir, ritonavir and saquinavir in human plasma by high-performance liquid chromatography-tandem mass spectrometry," Journal of Chromatography B, vol. 829, no. 1-2, pp. 82-90, 2005.

[38] R. Verbesselt, E. van Wijngaerden, and J. de Hoon, "Simultaneous determination of $8 \mathrm{HIV}$ protease inhibitors in human plasma by isocratic high-performance liquid chromatography with combined use of UV and fluorescence detection: amprenavir, indinavir, atazanavir, ritonavir, lopinavir, saquinavir, nelfinavir and M8-nelfinavir metabolite," Journal of Chromatography $B$, vol. 845, no. 1, pp. 51-60, 2007.

[39] D. R. Weller, R. C. Brundage, H. H. Balfour Jr., and H. E. Vezina, "An isocratic liquid chromatography method for determining HIV non-nucleoside reverse transcriptase inhibitor and protease inhibitor concentrations in human plasma," Journal of Chromatography B, vol. 848, no. 2, pp. 369-373, 2007.

[40] S. Notari, A. Bocedi, G. Ippolito et al., "Simultaneous determination of 16 anti-HIV drugs in human plasma by highperformance liquid chromatography," Journal of Chromatography B, vol. 831, no. 1-2, pp. 258-266, 2006. 

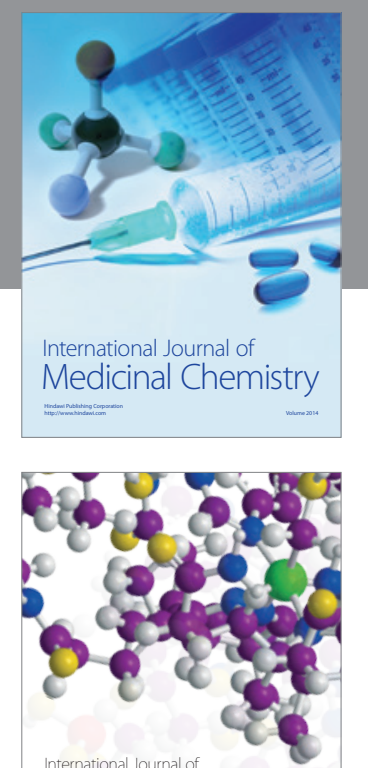

\section{Carbohydrate} Chemistry

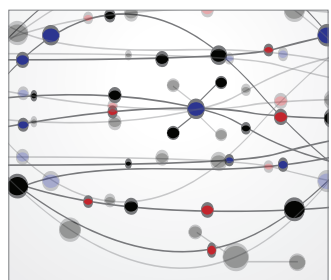

The Scientific World Journal
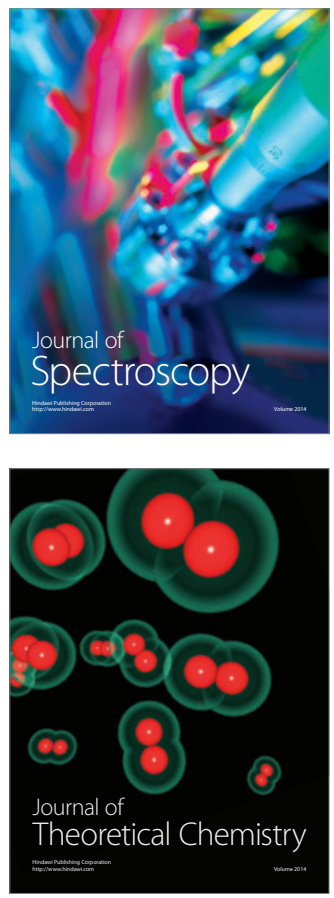
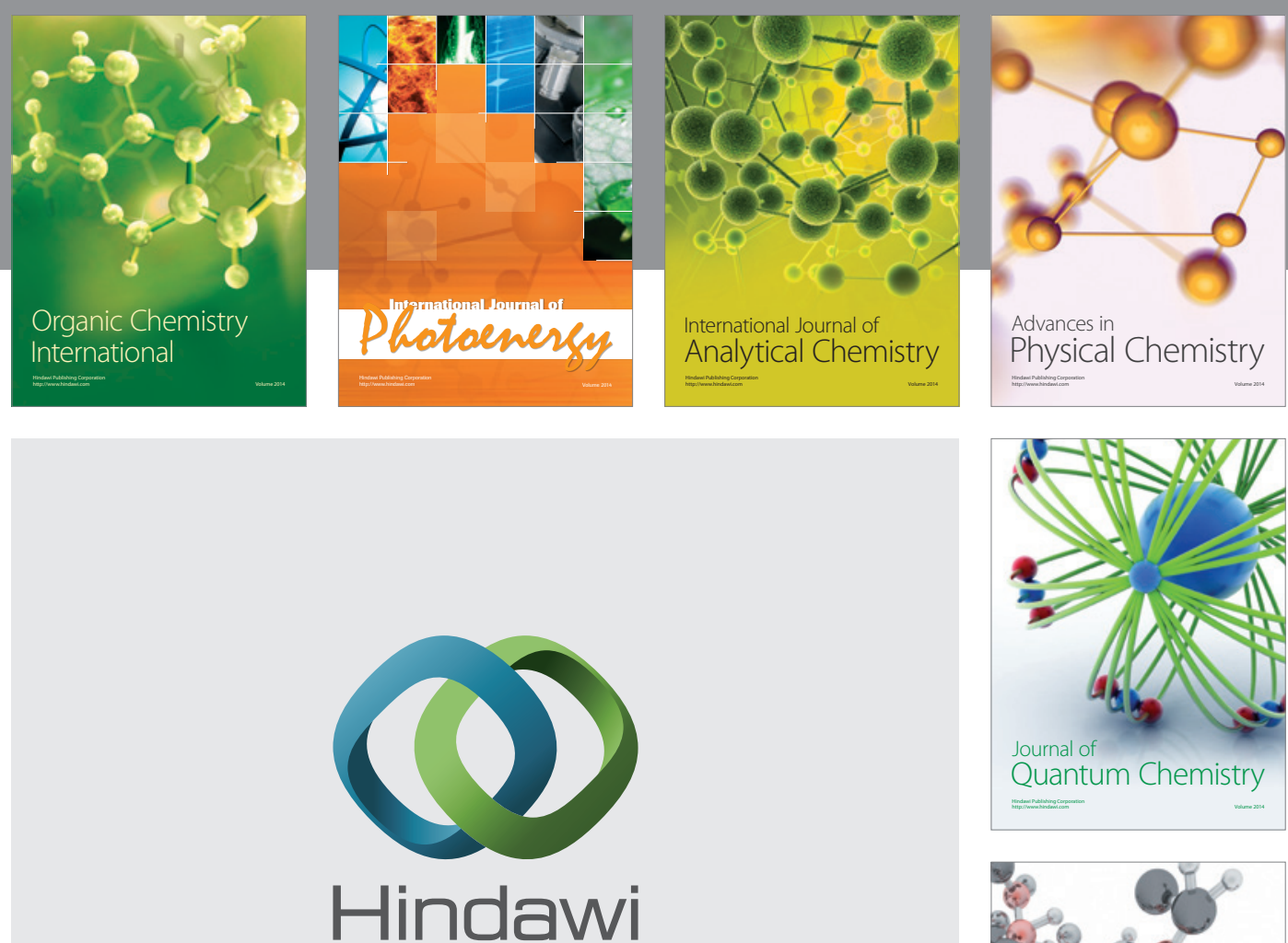

Submit your manuscripts at

http://www.hindawi.com

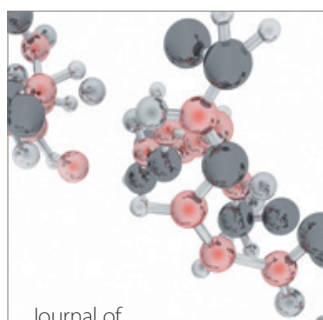

Analytical Methods

in Chemistry

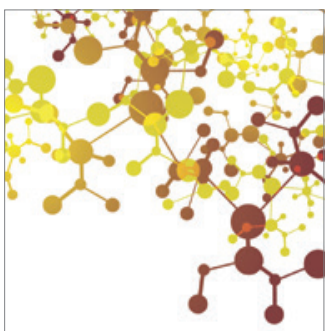

Journal of

Applied Chemistry

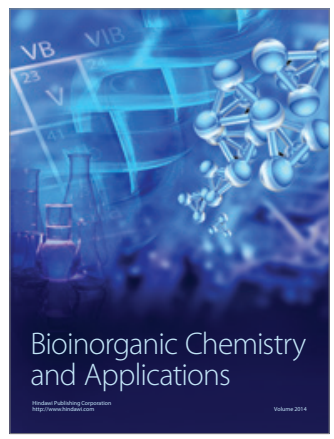

Inorganic Chemistry
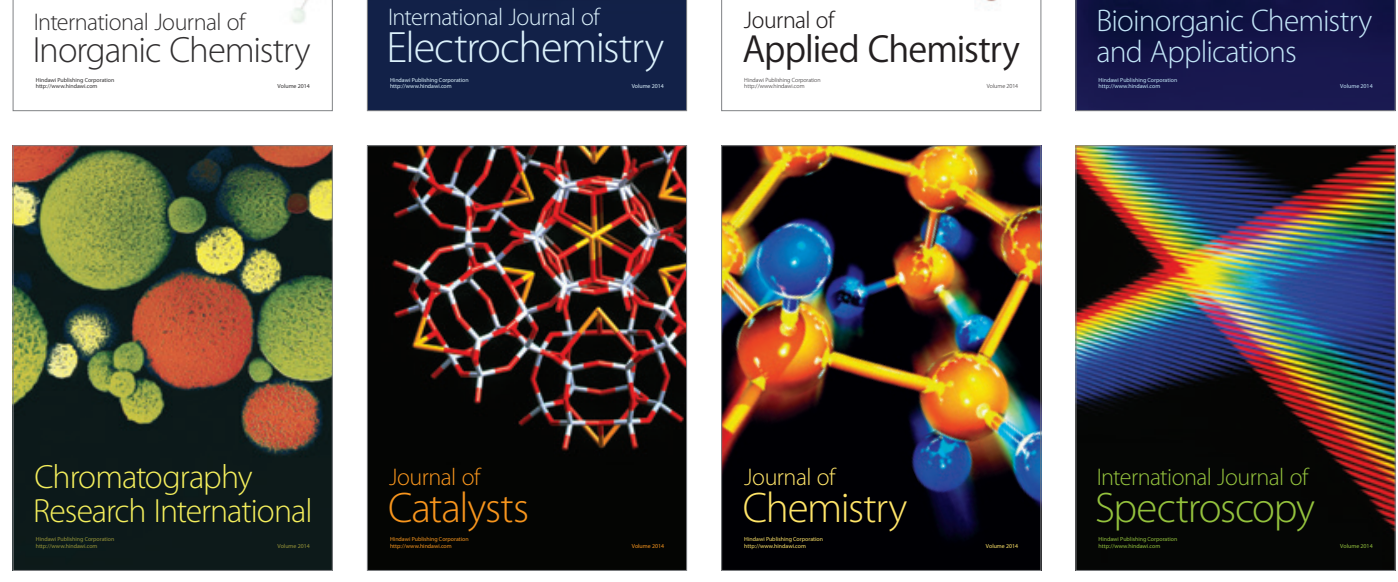